University of Nebraska - Lincoln

DigitalCommons@University of Nebraska - Lincoln

Biological Systems Engineering: Papers and

Publications

Biological Systems Engineering

2011

\title{
Evaluation of soil salinity leaching requirement guidelines
}

John Letey

University of California, Riverside,, john.letey@ucr.edu

Glenn J. Hoffman

University of Nebraska--Lincoln, ghoffman1@unl.edu

Jan W. Hopmans

University of California, Davis, jwhopmans@ucdavis.edu

Stephen R. Grattan

University of California, Davis, srgrattan@ucdavis.edu

Donald Louis Suarez

USDA Salinity Laboratory, Riverside,CA, donald.suarez@ars.usda.gov

See next page for additional authors

Follow this and additional works at: https://digitalcommons.unl.edu/biosysengfacpub

Part of the Biological Engineering Commons

Letey, John; Hoffman, Glenn J.; Hopmans, Jan W.; Grattan, Stephen R.; Suarez, Donald Louis; Corwin, Dennis L.; Oster, Jim D.; Wu, Laosheng; and Amrhein, Christopher, "Evaluation of soil salinity leaching requirement guidelines" (2011). Biological Systems Engineering: Papers and Publications. 215. https://digitalcommons.unl.edu/biosysengfacpub/215

This Article is brought to you for free and open access by the Biological Systems Engineering at DigitalCommons@University of Nebraska - Lincoln. It has been accepted for inclusion in Biological Systems Engineering: Papers and Publications by an authorized administrator of DigitalCommons@University of Nebraska Lincoln. 


\section{Authors}

John Letey, Glenn J. Hoffman, Jan W. Hopmans, Stephen R. Grattan, Donald Louis Suarez, Dennis L. Corwin, Jim D. Oster, Laosheng Wu, and Christopher Amrhein 
Review

\title{
Evaluation of soil salinity leaching requirement guidelines
}

\author{
J. Letey ${ }^{\mathrm{a}, *}$, G.J. Hoffman ${ }^{\mathrm{b}}$, J.W. Hopmans ${ }^{\text {c }}$, S.R. Grattan ${ }^{\mathrm{c}}$, D. Suarez ${ }^{\text {d }}$, \\ D.L. Corwin ${ }^{\mathrm{d}}$, J.D. Oster ${ }^{\mathrm{a}}$, L. Wu ${ }^{\mathrm{a}}$, C. Amrhein ${ }^{\mathrm{a}}$ \\ a Environmental Sciences Department, University of California, Riverside, CA 92521, United States \\ ${ }^{\mathrm{b}}$ Department of Biological Systems Engineering (Emeritus), University of Nebraska, Lincoln, NE, United States \\ ${ }^{c}$ Land Air and Water Resources Department, University of California, Davis, CA, United States \\ ${ }^{\mathrm{d}}$ USDA Salinity Laboratory, Riverside, CA, United States
}

\section{A R T I C L E I N F O}

\section{Article history:}

Received 26 April 2010

Received in revised form 5 August 2010

Accepted 12 August 2010

Available online 29 October 2010

\section{Keywords:}

Irrigation

Salt leaching

Steady-state analyses

Transient-state models

\begin{abstract}
A B S T R A C T
Water for irrigation is a major limitation to agricultural production in many parts of the world. Use of waters with elevated levels of salinity is one likely option to meet the supply of increased demands. The sources of these waters include drainage water generated by irrigated agriculture, municipal wastewater, and poor quality groundwater. Soil salinity leaching requirements that were established several decades ago were based on steady-state conditions. Recently transient-state models have been developed that potentially can more correctly predict the dynamics of the chemical-physical-biological interactions in an agricultural system. The University of California Center for Water Resources appointed a workgroup to review the development of steady-state analyses and transient-state models, and to determine whether the current recommended guidelines for leaching requirement based on steady-state analyses need to be revised. The workgroup concludes that the present guidelines overestimate the leaching requirement and the negative consequences of irrigating with saline waters. This error is particularly large at low leaching fractions. This is a fortuitous finding because irrigating to achieve low leaching fractions provides a more efficient use of limited water supplies.
\end{abstract}

(c) 2010 Elsevier B.V. All rights reserved.

\section{Contents}

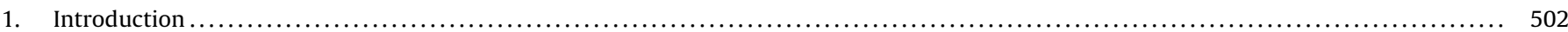

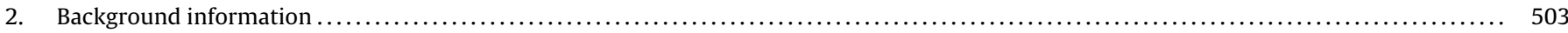

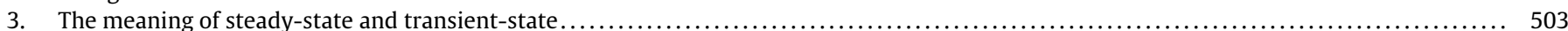

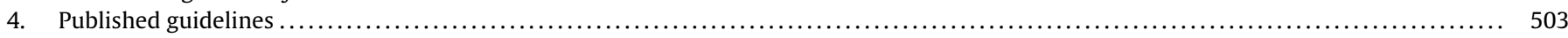

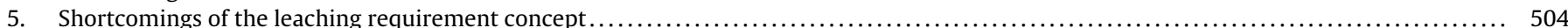

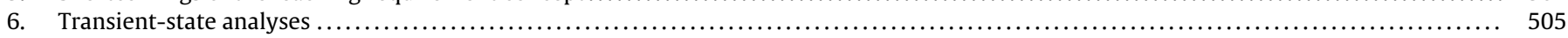

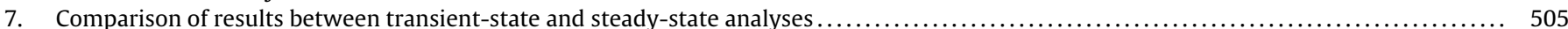

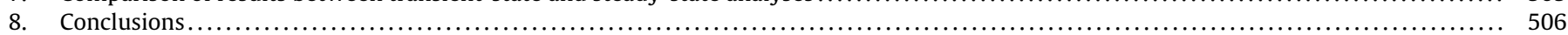

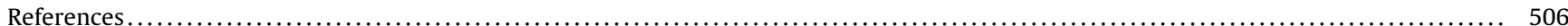

\section{Introduction}

Water for irrigation is a major limitation to agricultural production in many parts of the world. Irrigated lands produce more than $40 \%$ of the world's food and account for almost $90 \%$ of the global developed water consumption (Döll and Siebert, 2002). Moreover, the increase in human population has caused an increase in water demand for urban and agricultural purposes. Use of

\footnotetext{
* Corresponding author. Tel.: +1 951827 2560; fax: +1 9518274652

E-mail address: john.letey@ucr.edu (J. Letey).
}

waters with elevated levels of salinity is one likely option to meet the supply of increased demands. The sources of these waters include drainage water generated by irrigated agriculture, municipal wastewater, and poor quality groundwater. Irrigation with saline waters requires application of extra water for leaching of salts from the root zone to prevent excessive accumulation of salts that would limit the yield potential of crops. Thus a trade-off exists between applying more water for soil salinity control and applying less water to protect groundwater quality from the leaching of pollutants such as pesticides and nitrate, and making more water available for other purposes. Advancements in irrigation technology such as micro-irrigation and sprinkler systems provide the opportunity to irrigate with very low leaching fraction (LF) values. 
However, irrigating with low leaching fractions may lead to soil salination, thereby causing reduction in crop yield.

Irrigation guidelines that were established several decades ago were based on steady-state conditions, and are still widely used to assess the suitability of water for irrigation. These guidelines were established to develop simple relationships to estimate crop yield potential from irrigation water salinity and LF. Recently though, high-speed computers have facilitated the development of transient-state models that potentially can more correctly predict the dynamics of chemical-physical-biological interactions in natural agricultural systems, thereby more accurately assess spatio-temporal changes in soil salinity during and between growing seasons. Based on computer simulation results to date, there is a growing concern that the steady-state approach may overestimate the negative effects of saline irrigation water on crop production for a range of irrigation water management conditions, as will be elaborated on in this communication.

The University of California Center for Water Resources appointed a workgroup with the charges: (1) to review the development of steady-state analyses and transient-state models, (2) to answer the question, "Do the current recommended guidelines on leaching requirements (based on steady-state analyses) need to be revised?", and (3) if yes, draw up a new set of guidelines. This information is not only important to farmers, but also for regulatory agencies that apply or establish salinity standards for water bodies designed to protect agricultural production. This article reports the findings of the workgroup on the first two assignments.

Many articles have been published on managing saline irrigation waters, and each could be considered as providing guidelines. We chose to restrict our analyses to those presented in the Food and Agricultural Organization of the United Nations report by Ayers and Westcot (1985) that have been widely used internationally; and those of Hanson et al. (2006) published by the University of California, Division of Agriculture and Natural Resources as those promulgated by the University of California.

\section{Background information}

Salinity and its effects on a society have been traced back to ancient Mesopotamia (Jacobsen and Adams, 1958). Ancient history has recorded several major occurrences of salinity, but the earliest and one of the most serious occurred during 2400-1700 B.C. in what is now southern Iraq. Water was diverted from the Tigris and Euphrates rivers to irrigate fertile lands. Copious quantities of water were applied leading to water table rise and ultimate salination of the soil by capillary rise. Declining yields, abandoning salinized fields and shifts to cultivation of more salt-tolerant crops paralleled increasing soil salinity. The southern part of the alluvial plain never recovered from the decline resulting from salination. The land was converted from fertile soils to the present desert conditions.

These and other historical experiences have led to inclusion of subsurface drainage systems in irrigation projects to maintain water tables below the root zone, thereby allowing leaching of excess salts from the root zone. Since all irrigation waters contain salts and crops take up nearly pure water for transpiration (nutrients and some specific salts are taken up by the roots), salts will remain behind and concentrate in the crop root zone, thus requiring periodic leaching to move excessive salts downwards to avoid reduced crop yields. The fraction of the water amount that drains beyond the root zone relative to the amount of applied irrigation water is defined as the leaching fraction (LF).

The term "leaching requirement" (LR) has been defined as the minimum LF that is required over a growing season for a particular quality of water to achieve maximum yield of a given crop and has a specific quantitative value. It is not simply an abbreviated way of stating that leaching is required.

A large amount of research has been conducted in the past to assess crop salt tolerance. Much of that work was summarized for more than 60 agricultural crops by Maas and Hoffman (1977). They reported salt tolerance information using two parameters: the salt tolerance threshold value and the percent yield decline per unit increase in salinity beyond the threshold value. The Maas and Hoffman $(\mathrm{M}-\mathrm{H})$ coefficients continue to provide the scientific basis for irrigation management guidelines world-wide. Coefficients were related to the average root zone electrical conductivity of the saturated soil extract $\left(E C_{e}\right)$. Plants are expected to respond to the salinity of the water surrounding the $\operatorname{root}\left(\mathrm{EC}_{\mathrm{S}}\right)$. Since soils are typically at field capacity or at lower water content during the growing season, it has been commonly assumed that $\mathrm{EC}_{\mathrm{s}}$ is approximately equal to $2 \mathrm{EC}_{\mathrm{e}}$. Maximum yield is expected if the average root zone $\mathrm{EC}_{\mathrm{e}}$ is equal to or less than the $\mathrm{M}-\mathrm{H}$ threshold value $\left(\mathrm{EC}_{\mathrm{e}}^{*}\right)$. As reported hereafter, there is a direct connection between crop salt tolerance, irrigation water salinity, and leaching requirement.

\section{The meaning of steady-state and transient-state}

Mathematically a steady-state flow analysis does not include a time variable; whereas, a transient-flow analysis does. Considering a flow analysis of water and solute, the water content and solute concentration at a given point remains constant with time in a steady-state system and can vary in a transient-state system. However, many reports on managing saline irrigation waters do not adhere to this strict mathematical definition of steady-state.

In fact, "true" steady-state conditions never exist in the field. Steady-state specifies that applied irrigation water is continuously flowing downwards at a constant rate, irrespective of irrigation frequency. In addition, steady-state specifies that evapotranspiration is constant over the growing season. Consequently, steady-state solutions assume that the salt concentration of the soil solution at any point in the soil profile is constant at all times. None of these is real. However, some aspects of steady-state are observed in the field. If a given irrigation regime is followed for an extended period of time, the salt concentration below the root zone does become constant with time. Thus, a steady-state condition exists below the root zone even though transient conditions exist within the root zone. The law of conservation of matter combined with the assumption that there is no chemical precipitation or dissolution can be used to calculate the "steady-state" salt concentration below the root zone. The relationship is

$\frac{C_{\mathrm{dw}}}{C_{\mathrm{iw}}}=\frac{D_{\mathrm{iw}}}{D_{\mathrm{dw}}}$

where $C_{\mathrm{iw}}$ and $C_{\mathrm{dw}}$ are the salt concentrations of the irrigation water and drainage water at the bottom of the root zone, respectively; and $D_{\text {iw }}$ and $D_{\mathrm{dw}}$ are the depths of applied water and drainage water, respectively. Typically, the electrical conductivities of the irrigation and drainage waters are used for salt concentrations.

Furthermore, although the salt concentration distribution with depth in the root zone does vary with time, the pattern consistently repeats itself with time for a given irrigation regime that is followed for an extended period of time. This condition has sometimes been referred to as a steady-state condition. However, this is not a "true" steady-state condition and cannot be calculated from steady-state analysis. This condition can, however, be computed from a transient-state analysis.

\section{Published guidelines}

Ayers and Westcot (1985) clearly described the procedure they used in developing their guideline. They assumed that the depth 
Table 1

The average $\mathrm{EC}_{\mathrm{e}} / \mathrm{EC}_{\mathrm{w}}$ as a function of the leaching fraction for four steady-state models for use in determining the leaching requirement. A\&W refers to Ayers and Westcot (1985) and UC1 and UC2 refer to guidelines in Hanson et al. (2006).

\begin{tabular}{lllll}
\hline LF & A\&W & UC1 & UC2 & Eq. (2) \\
\hline 0.05 & 3.2 & 2.9 & 1.9 & 4.2 \\
0.10 & 2.1 & 2.0 & 1.4 & 2.2 \\
0.15 & 1.6 & & & 1.6 \\
0.20 & 1.3 & 1.5 & 1.1 & 1.2 \\
0.25 & 1.2 & & & 1.0 \\
0.30 & 1.0 & 1.0 & 1.0 & 0.85 \\
0.40 & 0.9 & 0.85 & 0.9 & 0.70 \\
0.50 & 0.8 & 0.75 & 0.75 & 0.60 \\
\hline
\end{tabular}

distribution of water uptake is $40,30,20$, and $10 \%$ of total crop transpiration, corresponding with the first through the fourth quarter sections of the root zone, respectively. Using mass balance considerations, the salt concentration in the soil solution $\left(\mathrm{EC}_{\mathrm{S}}\right)$ at the four quarter positions in the root zone were computed for LF values of 0.05 to 0.80 . The linear average of these root zone salinities was divided by 2 , thereby providing for an average root zone $\mathrm{EC}_{\mathrm{e}}$. The calculated average root zone $\mathrm{EC}_{\mathrm{e}}$ for each value of $\mathrm{LF}$ can be used, as will be illustrated later, to determine the LR based on irrigation water salinity and crop salt tolerance.

Ayers and Westcot (1985) also presented the following equation developed by Rhoades (1974) as a guideline for calculating LR based on irrigation water salinity and crop salt tolerance.

$\mathrm{LR}=\frac{\mathrm{EC}_{\mathrm{w}}}{5 \mathrm{EC}_{\mathrm{e}}^{*}-\mathrm{EC}_{\mathrm{w}}}$

where $\mathrm{EC}_{\mathrm{w}}$ is the electrical conductivity of the irrigation water.

Hanson et al.(2006) reproduced two graphs originally published by Rhoades (1999) showing the linear relationship between average root zone $\mathrm{EC}_{\mathrm{e}}$ and $\mathrm{EC}$ w for $\mathrm{LF}$ values between 0.05 and 0.50 . One graph was for conventional surface and sprinkler irrigation (UC1) and the other for high frequency irrigation methods (UC2) such as drip.

A comparison of the four guidelines for calculating LR using these steady-state approaches is presented in Table 1 . The numbers represent the ratio of the average root zone $\mathrm{EC}_{\mathrm{e}}$ to $\mathrm{EC}_{\mathrm{w}}$, thus quantifying the salt concentrating factor associated with each listed value of LF. These ratio values can be used to assess maximum allowable irrigation water salinity values, such that the soil salinity concentration will not exceed the $\mathrm{EC}_{\mathrm{e}}^{*}$ value for a specific crop (i.e. maximum crop yield). For example, consider a salt sensitive crop with an $\mathrm{EC}_{\mathrm{e}}^{*}$ value of $1 \mathrm{dS} / \mathrm{m}$ that is irrigated with a $\mathrm{LF}$ of 0.15 . The Ayers and Westcot (A\&W) concentrating factor of 1.6 would indicate that the salinity of the applied water cannot exceed $0.62 \mathrm{dS} / \mathrm{m}$ for maximum yield. By comparison, the irrigation water salinity must be $0.31 \mathrm{dS} / \mathrm{m}$ or less to achieve maximum yield if the LF is 0.05 . The A\&W, UC1, and UC2 models predict that maximum yield will be achieved using a LF of 0.3 when the irrigation water salinity is equal to $\mathrm{EC}_{\mathrm{e}}^{*}$ (Table 1 ).

The UC2 guideline has the lowest concentrating factors of the four guidelines, particularly at the lower values of LF. The UC2 guideline is based on high-frequency irrigation and a water-uptake weighted average $\mathrm{EC}_{\mathrm{e}}$ (Rhoades, 1999), whereas the others are based on a linear average.

Ayers and Westcot (1985) reported in detail their analyses that led to the values of Table 1 . Their analysis clearly demonstrates how root water uptake leads to a corresponding increase in soil salt concentration with depth, and to increasing soil salinity at a given depth as LF decreases. They show that the soil salinity values at the bottom of the rooting zone are greatly affected by LF values, and that the near-surface soil salinity is relatively least affected by the leaching magnitude. Their analysis clarifies that the method of linearly averaging to determine the average root zone soil salinity is most sensitive to the salinity in the lower parts of the root zone, where less root water is extracted.

The assumption that plants respond to a linear-average soil root zone EC is not supported by experimental evidence. Gardner (1983) in his review of plant root water-extraction patterns concluded that soil water is initially mostly extracted from the near soil surface regions where plant roots are most prolific, and that the zone of root water-extraction progresses downwards as soil water becomes more limiting in the upper soil zones. Furthermore, there is experimental evidence that plants will extract additional soil water from the less-stressed portions of the root zone to compensate for reduced root water uptake in the stressed root zone regions. For example, van Schlfgaarde et al. (1974) analyzed data from an alfalfa experiment and concluded "apparently as long as the roots have access to water of low salinity, they are able to utilize some water of higher salinity without adverse effects." Based on what is scientifically known about water uptake by plants, it can be concluded a priori that determining yield from the linear average of salinity in the root zone will likely result in an overestimation of the negative impact of soil salinity on crop yield.

Given the analysis above, one may argue the presence of an inconsistency in our reasoning. On one hand, the $\mathrm{M}-\mathrm{H}$ coefficients as reported are based on average root zone $\mathrm{EC}_{\mathrm{e}}$, yet the linear averaging of soil salinity by Ayers and Westcot (1985) is being considered as being at fault. This apparent contradiction is the result of the high leaching fractions used by the experiments analyzed by Maas and Hoffman (1977) to determine the salt tolerance levels. Under these conditions, the soil-water salinity is relatively constant with depth and is not concentrated greatly by plant water extraction. This condition differs largely from the high salt concentrations experienced in the deep root zones at low leaching fractions.

\section{Shortcomings of the leaching requirement concept}

Several shortcomings exist in the LR concept as has been proposed using steady-state analyses. The LR concept is based on achieving maximum yield. Maximum yields may not be the economically optimal yield. This is particularly true when only saline waters are available and potential maximum yields are not possible. Furthermore, there are situations, such as in the western San Joaquin Valley of California, where high costs are entailed in disposing subsurface drainage waters. Under these conditions there are economic benefits for reducing LF that must be considered in offsetting potential yield decreases. The relationships between water salinity, water application, crop yield, and the amount of drainage water are necessary to establish the optimal management strategy. The one-valued LR is not sufficient.

A steady-state analysis dictates that water is applied uniformly across the field at a constant rate and salinity. Clearly, such constant conditions are not realistic, but were required to obtain a simple leaching requirement solution. Rainfall or other forms of precipitation such as snow significantly moderates the consequences of irrigating with saline waters and evaluating its impact on crop yield is important. Only a few steady-state models consider rainfall. Moreover, crop rotations result in guidelines requiring differentiation between crops and years. Planting crops that vary in salinity tolerance is a common agricultural practice that cannot be incorporated into a steady-state analysis because of seasonal lag times associated with salinizing and desalinizing the soil profile. Leaching usually is not required for each irrigation event and this feature is not accommodated by steady-state analysis either.

Scheduling irrigation is most commonly based on accommodating potential ET (plant evapotranspiration) plus some extra for 
nonuniform irrigation and leaching purposes. Few if any actually calculate the amount of extra water needed to achieve a desired LF. Some assume that a $20 \%$ LF is achieved by applying $20 \%$ more water than ET. That is erroneous. The relationship between applied water $(\mathrm{AW}), \mathrm{ET}$ and $\mathrm{LF}$ is

$$
\frac{\mathrm{AW}}{\mathrm{ET}}=\frac{1}{1-\mathrm{LF}}
$$

A LF equal to 0.20 requires AW/ET to be 1.25 . Thus $25 \%$ more water than ET must be applied to get a $20 \%$ LF. A LF of $50 \%$ is achieved by applying twice the amount of ET. Potential ET (PET) is defined as the maximum daily or seasonal total plant ET, implying zero crop stress as caused by either reduced irrigation water application or by soil salinity. In Eq. (3), ET represents actual crop evapotranspiration. However, if defined in the context of computing irrigation LR with maximum crop yield, in fact, ET in Eq. (3) would be PET.

In addition, micro-irrigation systems typically apply water locally, thus wetting only part of the field soil surface. Consequently, field-wide application of Eq. (3) leads to underestimation of actual LF values. For example, Hanson et al. (2009) demonstrated that high efficiency of drip micro-irrigation that partially wets the soil surface area occurred only under conditions of severe deficit irrigation as determined from a field-scale water balance of tomatoes under shallow groundwater table conditions. Hence, LR guidelines must be adjusted, to allow for partial soil surface wetting and spatially variable salt accumulation.

\section{Transient-state analyses}

The advent of high-speed computers has facilitated the opportunity to develop models based on transient-state analyses. These models allow simulations that include temporal changes in crop, changes in crop salt tolerance through the growing season, water salinity including rain, and the amount of irrigation and rain that are consistent with actual conditions. Several models have been published in the literature. The workgroup developed a matrix to compare various features of the models. Some models have several features that are the same, but each has at least one component that differs from the others.

Models are only useful to the extent that they accurately simulate behavior in the field. Comparison between model simulations and experimental data from field experiments is important. Unfortunately because of the complexity and cost associated with field experiments that include both water salinity and other variables, not many field experiments have been conducted. Among the few, one was conducted at the Gilat Agricultural Experimental Station in the northern Negev of Israel on corn (Shalhevet et al., 1986). Five irrigation water salinities ranging from 1.7 to $10.2 \mathrm{dS} / \mathrm{m}$ were used along with four irrigation intervals ranging from 3.5 to 21 days. Feng et al. (2003) compared the experimentally measured yield to the simulated yields using the ENVIRO-GRO model. The mean simulated relative yield was 0.70 and the measured mean relative yield was 0.68 . The Willmott's index of agreement between simulated and measured yield was 0.96 (a value of 1.0 represents perfect agreement). Based on these results, the authors concluded that the ENVIRO-GRO model can be used with confidence in simulating the consequences of irrigation management options under saline conditions.

Another frequently used transient model is HYDRUS-2D, simulating movement of water and dissolved salts in soils. This model was used by Hanson et al. (2008) to compare results with field experiments on processing tomatoes under shallow water table conditions for both drip and sprinkler irrigation for a wide range of irrigation water salinities. Replicated experiments were conducted to investigate relationships among yield, irrigation water salinity and applied water. Both field and model results showed
Table 2

The AW/PET value calculated with ENVIRO-GRO (E-G) and several steady-state models to achieve maximum corn yield when irrigating with water of 1 and $2 \mathrm{dS} / \mathrm{m}$. A\&W refers to Ayers and Westcot (1985), UC1 and UC2 refer to guidelines in Hanson et al. (2006), and E-G refers to ENVIRO-GRO (Pang and Letey, 1998).

\begin{tabular}{lllllr}
\hline $\mathrm{EC}_{\mathrm{w}}$ & $\mathrm{A} \& W$ & UC1 & UC2 & Eq. (2) & E-G \\
\hline 1 & 1.19 & 1.19 & 1.11 & 1.15 & $<1.05$ \\
2 & 1.82 & 1.67 & 1.75 & 1.44 & 1.17 \\
\hline
\end{tabular}

that seasonal field-wide water applications should be about equal to seasonal ET, thereby providing adequate localized leaching at the crop root zone scale and preventing the shallow saline water table from rising.

\section{Comparison of results between transient-state and steady-state analyses}

Letey and Feng (2007) compared results of transient-state analysis using ENVIRO-GRO (Pang and Letey, 1998) with steady-state analyses for irrigating corn. The results presented in that paper are expanded here to include all of the steady-state models that are reported in Table 1. Transient-state models do not directly calculate LR. Instead, model simulations are conducted for a series of seasonal water applications, from which the lowest application is selected that maintains maximum crop yield, so that ET in Eq. (3) is PET. Thus the input is the ratio of AW to PET. Eq. (3) was used to convert LR to AW/PET or vice-versa. The results are presented in Table 2 for irrigating corn with water salinity values of 1 or $2 \mathrm{dS} / \mathrm{m}$. The $\mathrm{EC}_{\mathrm{e}}^{*}$ for corn was assumed to equal $1.7 \mathrm{dS} / \mathrm{m}$ (Maas and Hoffman, 1977). All steady-state methods predicted that more water had to be applied to achieve maximum yield as compared to ENVIRO-GRO. The differences were especially great at the higher water salinity.

Corwin et al. (2007) also reported that the calculated LR was lower when determined using a transient-state approach than when using a steady-state approach. They used TETrans and UNSATCHEM as their transient-state models. They calculated that the reduced LR using the transient-state analyses as compared to the commonly used traditional method for the Imperial Valley of California would result in a diminished drainage volume of approximately $125 \mathrm{Mm}^{3}$.

Some of the reasons that the transient-state simulations resulted in a lower required irrigation amount than the steady-state approaches to achieve maximum yield are as follows:

(1) The steady-state approach assumes that the plant responds to the average root zone salinity that increases greatly as the LF decreases. However, the major amount of water is extracted from the upper parts of the root zone where the salt concentration is not very sensitive to LF.

(2) The salt concentration at a given depth in the field does not remain constant with time as predicted by the steady-state models, but is continually changing as water is added or extracted by the plant. The salts become concentrated by water extraction, but irrigation water "flushes" the salts downwards and thus reduces the concentration to a lower value at a given depth after irrigation. The concentration immediately after irrigation near the soil surface would be close to the concentration in the irrigation water.

(3) For most soils, the volumetric soil-water content would be reduced by less than half between irrigations; thus, concentrating the soil water salinity by less than two between irrigations. Therefore, as a general guideline, irrigation water with a salt concentration equal to $\mathrm{EC}_{\mathrm{e}}^{*}$ can be used with a relatively low LF. This conclusion is based on the fact that the $\mathrm{M}-\mathrm{H}$ coefficients are based on $\mathrm{EC}_{\mathrm{e}}$ which is about $\mathrm{EC}_{\mathrm{s}} / 2$. The soil-water can there- 
fore be concentrated by a factor of two without exceeding the threshold value.

Chemical factors also impact the salinity in the root zone. Salt precipitation will affect the soil-solution salinity and the salt precipitating will be a function of irrigation water chemistry and soil chemistry. Precipitation of calcite occurs in almost all instances when irrigating in arid regions at low leaching fractions. This typically reduces the salt load by $5-25 \%$ at the bottom of the root zone and reduces the $\mathrm{EC}_{\mathrm{s}}$ throughout all but the upper portion of the root zone. For waters containing elevated sulfate and calcium concentrations, precipitation of gypsum will cause a major reduction in root zone $\mathrm{EC}_{\mathrm{s}}$. An additional factor reducing the $\mathrm{EC}_{\mathrm{s}}$ to below that predicted based on water budgets (as above) is the nonlinearity between EC of water and the actual concentration (the $\mathrm{EC} /$ salt concentration ratio decreases with increasing concentration). Additionally, if field measurements of soil $\mathrm{EC}_{\mathrm{e}}$ are made, and related to the salt tolerance tables, salinity impacts will again be overestimated. In this instance mineral dissolution (primarily gypsum if present) will release salts in the relatively dilute saturation extract.

All of the analyses presented here ignored rainfall. Rainfall at any time of the year would partially mitigate the impacts of irrigating with saline waters. Simulations using transient-state models for actual field conditions require input of all waters, including rain. Thus the impact of rain cannot be ignored using these models. The effect of rain can be estimated assuming quasi steady-state conditions and using the weighted-average salinity of combined rain and irrigation water. However, the other deficiencies of the steadystate analyses are not corrected by this procedure. For example in a model developed by Isidoro and Grattan (2010), simulations indicate that rainfall occurring mostly in the winter produced lower $\mathrm{EC}_{\mathrm{e}}$ values in the root zone than did rainfall evenly distributed throughout the year. This result suggests that temporal distributions of rain may have an important influence of seasonal root zone salinity.

\section{Conclusions}

The workgroup concludes that the present guidelines based on steady-state analyses overestimate the leaching requirements and the negative consequences of irrigating with saline waters. This error is particularly large at low leaching fractions. This is a fortuitous finding because irrigating to achieve low leaching fractions is desirable for the purpose of reducing the transport of chemicals that degrade groundwater quality and also provides for a more efficient use of limited water supplies. The feasibility of using saline waters for irrigation is also enhanced. Thus these positive goals can be pursued without an erroneous overestimate of developing soil salination. However, soil salination is still a potentially very negative consequence of irrigation and cannot be ignored.

\section{References}

Ayers, R.S., Westcot, D.W., 1985. Water Quality for Agriculture. FAO Irrigation and Drainage Paper 29. Food and Agriculture Organization of the United Nations, Rome, p. 174

Corwin, D.L., Rhoades, J.D., Simunek, J., 2007. Leaching requirement for soil salinity control: steady-state versus transient models. Agric. Water Manage. 90, 165-180.

Döll, P., Siebert, S., 2002. Global modeling of irrigation water requirements. Water Resour. Res. 38 (8), doi:10.1029/2001WR000355.

Feng, G.L., Meiri, A., Letey, J., 2003. Evaluation of a model for irrigation management under saline conditions. I. Effects on plant growth. Soil Sci. Soc. Am. J. 67, 71-76.

Gardner, W.R., 1983. Soil properties and efficient water use: an overview. In: Taylor, H.M., Jordan, W.R., Sinclair, T.R. (Eds.), Limitations to Efficient Water Use in Crop Production. American Society of Agronomy, Madison, WI, pp. 45-64.

Hanson, B.R., Grattan, S.R., Fulton, A., 2006. Agricultural Salinity and Drainage, revised ed. Division of Agriculture and Natural Resources Publication 3375 University of California, p. 164.

Hanson, B.R., May, D.E., Simunek, J., Hopmans, J.W., Hutmacher, R.B., 2009. Drip irrigation increases the profitability of tomatoes in the San Joaquin Valley and may eliminate the need for drainage-water disposal facilities. Calif. Agric. 63 131-136.

Hanson, B.R., Simunek, J., Hopmans, J.W., 2008. Leaching with subsurface drip irrigation under saline, shallow groundwater conditions. Vadose Zone J. 7 (2), 810-818.

Isidoro, D., Grattan, S.R., 2010. Predicting soil salinity in response to different irrigation practices, soil types and rainfall scenarios. Irrig. Sci. doi:10.1007/s00271-010-0223-7.

Jacobsen, T., Adams, R.M., 1958. Salt and silt in ancient Mesopotamian agriculture. Science 128, 1251-1258.

Letey, J., Feng, G.L., 2007. Dynamic versus steady-state approaches to evaluate irrigation management of saline waters. Agric. Water Manage. 91, 1-10.

Maas, E.V., Hoffman, G.J., 1977. Crop salt tolerance-current assessment. J. Irrig. Drain. Div. ASCE 103 (IR2), 115-134.

Pang, X.P., Letey, J., 1998. Development and evaluation of ENVIRO-GRO: an integrated water, salinity, and nitrogen model. Soil Sci. Soc. Am. J. 62, 1418-1427.

Rhoades, J.D., 1974. Drainage for salinity control. In: van Schilfgaarde, J. (Ed.), Drainage for Agriculture. Am. Agron. Soc. Monogr., vol. 17, pp. 433-462.

Rhoades, J.D., 1999. Use of saline drainage water for irrigation. In: Skaggs, R.W., van Schlfgaarde, J. (Eds.), Agricultural Drainage. Agron. Monogr., vol. 38. ASA-CSSASSSA, Madison, WI, pp. 615-657.

Shalhevet, J., Vinten, A., Meiri, A., 1986. Irrigation interval as a factor in sweet corn response to salinity. Agron. J. 78, 539-545.

van Schlfgaarde, J., Bernstein, L., Rhoades, J.D., Rawlins, S.R., 1974. Irrigation man agement for salt control. J. Irrig. Drain. Div. ASCE 100 (IR3), 321-338 (Proc. Paper 10822). 